\title{
Una nueva propiedad intelectual para el siglo XXI. Focos, críticas y propuestas puntuales para una futura regulación de los bienes inmateriales
}

\author{
Guillermo Castro Ayala* \\ Recibido: 20 de julio de 2017 • Aprobado: 12 de octubre de 2017
}

\section{Resumen}

La consultación del estado del arte pareciera sugerir que la regulación del internet, en tanto tiene que ver con la propiedad intelectual, es un desafío tan avasallador que lentamente ha tomado un cariz anómico que no solo es peligroso, sino depresivo, si se contempla desde la perspectiva del autor en la red.

En el presente texto se analiza la problemática y plantea puntuales soluciones en diversos estados de tiempo. El derecho comparado y la historia del derecho han sido insumos que se han utilizado, tratando de sugerir evidencias que parecieran fácilmente aplicables, a pesar de la resistencia de la opinión mayoritaria de la doctrina.

Palabras clave: anomia, regulación, internet, derechos de autor, tasas, tarifa plana, renovación normativa.

\footnotetext{
"Artículo producto del proyecto de investigación: "Transferencia electrónica de fondos", gestionado en la Universidad Santo Tomás, Bogotá, Colombia. DOI: https://doi.org/10.15332/s19000448.2018.0048.01

" Abogado y magíster de la Universidad Nacional de Colombia, LL.M. y doctor de la Universidad de Konstanz en la República Federal de Alemania. Profesor por concurso de la Universidad Nacional de Colombia. Profesor de la Universidad Santo Tomás, Bogotá, Colombia. Exmagistrado auxiliar del Tribunal Superior de Bogotá, ex auxiliar de la Corte Suprema de Justicia. Correos electrónicos: jgcastroa@ unal.edu.co, jose.castro-ayala@uni-konstanz.de
} 


\title{
A NEW INTELLECTUAL PROPERTY FOR THE 2IST CENTURY. FocUSES, CRITICISMS AND SPECIFIC PROPOSALS FOR A FUTURE REGULATION OF INTANGIBLE ASSETS
}

\begin{abstract}
The consultation of the state of the art seems to suggest that the regulation of internet, insofar as it concerns intellectual property, is such an overwhelming challenge that it has slowly taken an anomie appearance that is not only dangerous, but depressive, if seen from the perspective of the network author.

The text analyzes the problem and proposes specific solutions in various stages of time. Comparative law and legal history are inputs that have been used, trying to suggest evidence that seem easy to apply, despite the resistance of the majority of the doctrine's opinion.
\end{abstract}

Keywords: Anomie, regulation, internet, copyright, rates, flat rate, renovation of regulations.

\section{UMA NOVA PROPRIEDADE INTELECTUAL PARA O SÉCULO XXI. Focos, CRÍTICAS E PROPOSTAS CONCRETAS PARA UMA FUTURA REGULAÇÃO DOS BENS IMATERIAIS.}

\section{Resumo}

A consulta do estado da arte parece sugerir que a regulação na internet, no relacionado com a propriedade intelectual, é um desafio tão avassalador que lentamente adquirido um cariz anomico que não só e perigoso, senão depressivo, se contempla desde a perspectiva do autor na rede.

No presente texto analisa-se a problemática e expõe soluções concretas em diversos estados de tempo. O direito comparado e a história do direito têm sido insumos que se tem utilizado, tentando sugerir evidencias que parecessem facilmente aplicáveis, apesar da resistência da opinião majoritária da doutrina.

Palavras-chave: anomia, regulação, internet, diretos de autor, taxas, tarifa plana, renovação normativa. 


\section{Introducción}

Luego de la celebración de más de 14 tratados de libre comercio, pareciera que Colombia debería buscar puntos focales regulatorios de ciertos temas, como la propiedad intelectual. Para ello, el derecho comparado se muestra como una inicial e ideal fuente de ideas. La utilización de esos instrumentos sobre los contenidos en internet, pareciera ser un punto que a corto plazo podría ser susceptible de ser unificado, creando patrones básicos regulatorios, ante lo cual el mejor y más amplio aprovechamiento de los contenidos, el beneficio del uso de los mismos y su obligatoria remuneración parecen ser elementos fundantes en el cambio de paradigma de la propiedad intelectual ${ }^{1}$.

\section{Colombia en el contexto jurídico-mercantil trasnacional: problemática y propuesta comparatista}

Colombia ha suscrito en un tiempo récord alrededor de 14 Tratados de Libre Comercio. Ese preciso dato fáctico implica que para bien o para mal, la normatividad colombiana en muchísimos aspectos tendrá que verse reinterpretada, como bien lo reflejan los paros agrarios y de transporte, que para cuando se escriben estas líneas, agobian al país (finales de agosto del 2013). En ese marco de trasnacionalización del derecho, la propiedad intelectual ha jugado, como es sabido, un papel protagónico; si no se olvida que de acuerdo a las inveteradas formas, protocolos y dinámicas de ese tipo de negociaciones, una unificación jurídica y económica es propuesta por parte de los países desarrollados (interesados en proteger, a ese respecto, productos manufacturados y conocimientos industriales o las más variadísimas formas del entretenimiento), y generalmente esa propuesta es aceptada por los países de la periferia, sin mayores reveces a través de una o muchas reformas legislativas que adecúan sus ordenamientos internos a las respectivas exigencias.

Desde esa perspectiva, es claro que sendas modificaciones, por lo menos en la reinterpretación de la normatividad colombiana sobre 4 diversas formas jurídicas como mucho, parece impensable (además de imposible), si se tienen en cuenta las distintas familias de derecho a las que pertenecen los países con los cuales se han

${ }^{1}$ Véanse entre otras, las siguientes páginas: http://www.tlc.gov.co/publicaciones.php?id=5398 o por otro lado: http://www.semana.com/economia/articulo/con-acelerador-fondo-tlc/346478-3 
suscrito acuerdos (p. ej. y fundamentalmente el sistema del common law, sistema continental europeo); pero una mínima adecuación normativa que case con todas las diversas familias jurídicas que empiezan a integrar y desarrollar esa dinámica de compatibilidades y afinidades, sí se presenta a lo sumo como necesaria a mediano plazo. Sobre esta problemática, véase en parte, Lipszyck (2006, p. 60).

En esa medida, entre otros muchos aspectos a tener en cuenta, el derecho comparado juega entonces un papel decisivo (no por cuanto debamos aceptar que una de las 14 propuestas reformatorias al respecto deba primar sobre las otras, en todos los aspectos regulados por los recientes acuerdos), sino por cuanto, atendiendo al hecho de que la globalización es un fenómeno social imparable, le compete entonces a Colombia, en el marco de la permanente edificación de su —así llamado—bloque de constitucionalidad y de contención de regulaciones indeseadas, determinar cuál es la más adecuada forma de permitir que se produzca el engrane jurídico general entre las normatividades foráneas y la propia, sin permitir - en principio- la afectación ni de los derechos fundamentales, ni de la arquitectura constitucional, bajo ninguna circunstancia.

Así pues, parece prudente ahondar desde ahora en los estudios comparados que delimiten perspectivas (abordando entonces las problemáticas desde un punto de vista objetivo y apriorístico) que a su turno permitan, en una primera instancia, una discusión lo más objetiva y amplia posible con el respectivo interlocutor y a mediano plazo articular de la manera más adecuada posible dos ejes: a) uno jurídico: entre los dos (o más) ordenamientos jurídicos del país o confederación correspondiente (piénsese en la Unión Europea o en Nafta) y el sistema jurídico nacional; b) otra articulación de ese nuevo derecho (que surja), con las dinámicas de la realidad social nacional que, se asume, debe ser protegida, desde el instrumentario constitucional. En otras palabras, la implementación de normas, luego de una discusión paritaria, se va a posibilitar más, en la medida en que la argumentación nacional sea tan rigurosa y sólida como se pueda².

${ }^{2} \mathrm{Al}$ respecto, es importante analizar la crisis de legitimidad del poder y del derecho, "sosteniendo la idea principal de que en la actualidad estamos viviendo una etapa de crisis del modelo jurídico" (Hurtado, 2017, p. 21). 


\section{El desbordamiento del tratamiento discursivo de la propiedad intelectual y las protestas: descripción}

Las modernas tecnologías permiten hoy en día al usuario copiar y distribuir muchos más bienes protegidos por la propiedad intelectual que hace 50 años (Lipsyzc, 2006, p. 55). Podría afirmarse, sin temor a equivocaciones, que el actual derecho de autor no protege de manera efectiva al titular de los respectivos derechos. En los países desarrollados existe algún grado de acuerdo en cuanto a que la comprensión del derecho de autor debería ser fundamentalmente reformada, para poder rescatar a los creadores, esto es, para poder lograr que sus derechos sean permanentemente lo menos afectados posible por los usuarios privados ${ }^{3}$.

El derecho de autor es hoy en día una de las áreas de regulación jurídica más controvertidas. Hace tiempo que ese derecho transmutó y migró en su esencia de las discusiones puramente jurídicas especializadas a discusiones públicas bastante complejas. Así, resulta llamativo cómo el derecho de propiedad intelectual exacerba los ánimos; cómo reconduce a controversias y discusiones que en una medida permiten hablar de "las guerras del derecho a la copia" "copyright wars". Las intenciones regulatorias como la Stop Online Piracy Act (SOPA) y la Prevent Internet Piracy Act (PIPA) en los Estados Unidos de Norteamérica, o la así llamada Anti-Counterfeiting Trade Agreement (ACTA) que produjeron masivas protestas alrededor de todo el mundo. Existen de hecho varios grupos en Facebook que se denominan "sopa pipa acta protest" y que, al parecer, entre otros muchos masamedia o medios masivos de intercomunicación, han permitido organizar alrededor del mundo las manifestaciones.

Escondidos tras nombres como Anonymus u otros boicoteadores internos o internacionales de la red, y a través de los llamados ataques DOS a los servidores de las sociedades de gestión colectiva de Inglaterra, Estados Unidos o diversos países europeos, miles de ciudadanos manifiestan su insatisfacción ante las políticas

${ }^{3}$ Entre otros ver los siguientes enlaces:

http://www.heise.de/newsticker/meldung/Ein-weiteres-Koerbchen-zur-Urheberrechtsreform1807860.html

https://netzpolitik.org/2013/urheberrechtrechtsreform-zwischen-geheimverhandlungen-undcrowdsourcing/

http://irights.info/urheberrechtsreform-in-kanada 
dominantes de los establecimientos gubernamentales. Partidos políticos de abierta protesta como los indignados en España y Francia o los piratas en Alemania han generado protestas y revueltas políticas, que entre otras cosas han empezado a tener un lugar ya sea en la cotidianidad mediática, o incluso en los parlamentos de importantes democracias occidentales.

\section{Las cuestiones nucleares}

Sin embargo, si obviamos muchas reflexiones coyunturales o accesorias, se considera que la principal cuestión se contrae a cómo en semejante escenario de escalamiento del conflicto discursivo y de sabotaje, en contra de las políticas transnacionales y de permanentes protestas podría retornarse, en relación al tema, a un discurso especializado nuevamente (jurídico-económico); y en qué medida el retorno a ese discurso podría jugar un papel significativo y serio en la materia.

En países del primer mundo, si hace 20 años se hubiese realizado una encuesta sobre el derecho de autor y de inventor, quizás se hubiese llegado a la conclusión de que un muy bajo porcentaje de la población tenía idea de que algo parecido existía en el ámbito jurídico o técnico, y mejor aún, que algo parecido pudiera afectar su vida diaria (solo los ingenieros y abogados tenían alguna conciencia al respecto). Todo esto se vio considerablemente modificado con la aparición e implementación del internet como medio de comunicación, e incluso podría decirse, que con la aparición de la así llamada “web 2.0.” (Kreutzer, 2013).

\section{El significativo cambio del derecho de autor en internet}

El fundamento esencial para la masificación de las discusiones sobre el derecho de autor es evidentemente su cambio de significación frente a la sociedad. Luego de esa significativa redefinición y hasta ahora, en manera alguna, se le ha brindado una atención juiciosa a través de regulaciones jurídicas que se compadezcan con la complejidad del rampante fenómeno. En este sentido, es importante anotar que, sin lugar a equívocos, no hay duda de que la conectividad y el acceso a nuevas tecnologías de información han crecido vertiginosamente en Colombia (Gómez, 2017). 
Para contextualizar esas afirmaciones, es necesario comenzar por decir que el derecho de autor surgió en sus fundamentos y en sus formas de manifestaciones más significativas, en tiempos en los que él, per sé, pretendía en realidad muy poco: el pago de unos réditos a quien generaba conocimiento y la perpetuación de la mención de su autoría. Consecuentemente fue concebido como una materia, que si bien era poco pretensiosa (aquella que otorgaba determinados privilegios), a la vez, implicaba que su diseño fuera altamente específico (Allfeld, 1999, pp. 8-12). Los mecanismos de regulación del derecho de autor son subdimensionados a normas especializadas dirigidas a muy determinados sujetos, como la empresa o la agencia profesional, la industria fílmica y musical, la sociedad de gestión colectiva y la economía editorial, entre otros (Allfeld, 1999).

En los mejores escenarios comparativos de los diversos ordenamientos pertenecientes al sistema continental europeo (Alemania, Suiza, Austria, en una menor medida Italia y Francia), unas sociedades de valoración especializadas y unos creadores (que se presuponían) con altos grados de innovación, profesionales representados por abogados superespecializados, se encargaban de materializar los derechos tanto morales como patrimoniales de los creadores. Esta concepción fue funcional (se podría decir incluso que bastante adecuada), hasta cuando el usuario privado de la obra (quien paso a paso aumentaba sus disimiles, formas de uso y aprovechamiento de los contenidos) no fue directamente sujeto de sanciones claras por un derecho de autor, que a la inversa, poco a poco, empezó a perder su esencia fundacional ante la aparición de medios técnicos cada vez más sofisticados y complejos.

Esta descripción de una relativa adecuación del estado de cosas resulta plausible hasta más o menos la mitad del siglo XX. A partir de allí los particulares tuvieron la capacidad, ya en sentido estricto, de utilizar trabajos protegidos por la propiedad intelectual en el sentido de "derecho de autor" de formas novedosas y diversas, pues había un vacío en todo el espectro de las tecnologías de la reproducción, grabación y difusión doméstica que, desde Berna, solo vinieron a ser analizadas (o reguladas) de manera tardía hacia 1967 (Ficsor, 2004, pp. 39-43).

Todas estas nuevas posibilidades son actividades que el derecho de propiedad intelectual no comprendía, porque el verdadero "disfrute del trabajo" no representaba una utilización relevante (ni violatoria en sentido estricto) protegida o regulada por el derecho de autor. Recién con la aparición de las primeras tecnologías multifuncionales, en especial con los aparatos de radio y de reproducción de cintas, se produjeron los primeros choques entre los particulares que usaban dichas tecnologías 
y los derechos de propiedad intelectual. También las copias privadas fueron por un periodo de tiempo considerable tan fáciles de obtener que el usuario - en general - no se percataba, en primer lugar, ni de que existía un derecho a obtenerla; en segundo lugar, de que no era un derecho absoluto a su favor.

Entre otros recursos regulatorios, los más lúcidos legisladores del mundo se sirvieron entonces de una construcción tan genial como consecuente: se creó el así llamado límite de la copia privada, que cubría todas las utilizaciones de aquellos consumidores que en ese entonces estaban en capacidad de acceder a esa misma copia privada (grabar música, sacar fotocopias, etc.). Para retribuir en debida forma al creador, se inventó entonces la así llamada en el primer mundo europeo: "cuota para los aparatos y medios de reproducción y grabación vacíos”, con lo que una pequeña parte adicionada por el legislador al precio de venta final de los aparatos multifuncionales, en especial de reproducción y grabación, así como del papel blanco especial que inicialmente se diseñó para esas máquinas, era reconducida por parte de las sociedades de gestión colectiva a los titulares últimos de los derechos.

Así, se produjo el siguiente fenómeno, que por lo demás resulta muy interesante, en perspectiva: el usuario no era capaz de percibir esa contribución, pero tampoco podía evadirla. Lo cual, sin embargo, no aportaba en medida alguna a la verdadera discusión pública. En consecuencia, las discusiones sobre las afectaciones al derecho de propiedad intelectual a duras penas resultaban comprensibles para los usuarios privados de las creaciones. En un mundo que, si bien se adjetivaba como desarrollado, resultaba en realidad un poco inasible la noción de "contribuciones ciertas (y conscientes)" a la propiedad intelectual. Todo lo anterior, ocurrió por vez primera (judicialmente y luego por vía de legislación) en la República Federal de Alemania, que a lo largo de este texto se vuelve entonces un referente obligatorio (Lipszyc, 2006, pp. 241-244).

Una figura similar tiene lugar en la legislación española, denominada como: canon digital, en cuyo caso funge como una compensación preventiva por copia privada sobre los equipos de reproducción digital, buscando producir un efecto equivalente al fenómeno antes decreto, pero que igualmente su aplicación ha resultado problemática (Tato, 2008).

La relevancia del derecho de autor para los particulares se modificó. Posteriormente, pero de manera mucho más significativa con la disponibilidad de las conexiones a internet, a favor de los consumidores domésticos y en general privados. A través de todas las tecnologías digitales actuales como el computador o los 
teléfonos móviles inteligentes y su conexión a internet, puede cada persona del planeta, en el entretanto, no solo ser usuario y creador, sino también productor, traductor y distribuidor de material intelectual: tomarse fotos, hacerlas circular en internet, copiar fotos de otras miles de páginas web en la red y colgarlas en blogs, cuentas y páginas propias; descargar textos, música, películas; realizar collages digitales, modificar y mejorar fotos, videos caseros, remix de música; subir información y datos para mostrarlos y compartirlos con alguien.

Lo anterior nos lleva claramente a la siguiente reflexión: al ser internet y su ilimitado acceso medios de infinitas oportunidades creativas y de distribución del conocimiento, incluso en términos globales, debería entonces tomarse esa realidad que condensa súbitamente la nueva concepción del derecho de autor como paradigma inicial de estudio.

Algo que resulta digno de aclaración, es que en términos latos no es "culpa" del ciudadano común su "eventual violación permanente del derecho de autor". En efecto, aplicar el principio de que "la ignorancia de la ley, no excusa de su complimiento" a rajatabla, resulta en términos políticos y de búsquedas de consenso algo inoportuno si se parte del marco necesario, planteado además por los expertos en el derecho de autor, de la revalidación del derecho de autor. Buscar como responsable último al ciudadano, que bombardeado por posibilidades técnicas antes inimaginables, accede a utilizarlas para aligerarse la vida en muchas oportunidades, solamente es un recurso desesperado de quienes se resisten a comprender cabalmente el problema. Las personas, en principio, solo hacen lo que siempre han hecho: son creativas y se comunican entre ellas, por supuesto también comunican su creatividad, intercambian con los otros sus propios avances y comparten lo que ellos han descubierto o han creado. Al respecto, Eco (2007) nos muestra entre otras muchas reflexiones al respecto, una que nos conmina a poner mientes en el asunto, para otorgar calificativos más precisos a cada elemento dentro de ese interesante fenómeno (p. 123).

La mala noticia para los reguladores enfermizos y sancionatorios de la propiedad intelectual jurídico-económicos es que solo se ha cambiado el medio técnico, (ahora muy veloz), a través de cual estas prácticas sociales y culturales pueden ser ejercidas. El intercambio de datos sobre las redes corresponde — aun a pesar de que los efectos para el titular de los derechos puedan volverse muy complejo- al esquema de comportamiento desde el ánimo de compartir todo lo que se conoce (to sharing), y que resulta explicable bajo el simplísimo ejemplo de un casete, que 
luego de ser grabado con música de una estrella de rock, es intercambiado en el patio de una escuela. Todo lo anterior, no obstante, para admitir que el derecho de autor debe ser visto de otra manera, ante la multiplicidad de formas novedosas que existen para compartir información online.

Esta ampliación del área de aplicación del derecho de autor, por supuesto reconduce a fricciones de consideración. Por un lado, resulta evidente que se deben presentar dificultades, cuando las leyes altamente especializadas, cuyo destinatario inicial era un experto, deben ser analizadas por un ciudadano del común. No menos claro también resulta que los valores de una regulación legal deben ser reordenados y repensados: si el círculo de destinatarios de la norma en un cortísimo tiempo se amplió de un muy pequeño grupo de expertos altamente especializados en cada país, a un grupo de millones o incluso de miles de millones de particulares en toda la aldea global (que además de compleja, entre otras cosas, se torna más y más cuestionada, entre otras razones, por cuanto termina exigiendo imposibles a los más desprevenidos ciudadanos), es claro que pueden presentarse dificultades interpretativas, aplicativas y ejecutivas en cuanto a los derechos que la misma norma confería (Beck, 2008, p. 219).

Ante el hecho de que el derecho de autor hasta ahora se encuentra muy alejado de articular la complejidad descrita, es dable argüir que dos aspectos fundamentales han de ser considerados de manera proporcionada. La causa fundamental para la recién descrita arriba "guerra de derechos a la copia" estriba fundamentalmente en haber obviado algunos puntos esenciales. Valga decir que no resulta reconocible hasta ahora la más mínima voluntad política para que se articule la nueva función social del derecho de autor y las modificaciones que con ella, en la gran constelación de intereses diversos han de reconocerse. Por lo menos no hay una mínima correspondencia en ese tratamiento legislativo o jurisprudencial que se compadezca con la realidad, ni hay indicaciones claras de iniciativas políticas que determinen al derecho de autor como un derecho comportamental general (que es en lo que se ha convertido, por lo menos a nivel de la red) y que lo "simplifiquen tan fuertemente", al punto de que se convierta en (y pueda servir como) una especie de "código de tránsito" para moverse en la red y de alguna propositiva forma, reorganizar la misma.

Los últimos quince años del desarrollo epistemológico y disciplinar del derecho de autor, se han impregnado de diversos leitmotivs. Desde el punto de vista del titular beneficiario de los derechos, internet fue desde el principio (y pareciera que para siempre) entendida solo como una amenaza, y en consecuencia tratada 
de esa misma forma. La política legislativa se ocupó desde ese momento (casi que exclusivamente) de la cuestión de cómo podía lucharse contra la piratería online (Kreutzer, 2013).

De momento, en las esferas internacionales se reconducen los análisis de reforma del derecho de autor renunciando a esa metodología (optimización del sistema y a desarrollar regulaciones modificadas sancionatorias) y reencausándola hacía cómo el derecho actual de autor puede ser mejor ejecutado (realizado en términos de ejecución decisional, en inglés: to enforce). De lo anterior, se sigue claramente, que un derecho que debe ejecutarse o ser exigido respecto de miles de millones de personas simultáneamente, debe contener déficits que solo pueden ser eliminados a través de modificaciones conceptuales de manera permanente.

Sin embargo, todo esto es tan poco evidente para los sectores políticos y los círculos de lobbystas de la economía de la innovación, como el hecho de que las modificaciones permanentes sirven o afectan a todos los actores de esas dinámicas (autores, usuarios, sociedades de gestión, intermediarios) y que la adecuada regulación del asunto es necesaria para todos (de manera incondicional).

\section{Los desafíos}

Frente a este escenario, muchos expertos y científicos del derecho de autor se han puesto de acuerdo en que toda la tarea pendiente descrita no se ha de lograr con mejoras minuciosas y detalladas en el derecho de autor. Un derecho de autor para el siglo xxi debe compensar una inmensa pluralidad de intereses. Por supuesto, debe tener en cuenta, por sobre todo, los de aquellos que con sus creaciones intelectuales o con sus producciones, ganan dinero y quieren amortizar investigaciones, pero también los intereses de la generalidad de personas: del conglomerado social. Lo recién descrito es ya de por sí demasiado polifacético y complejo, pero además de ello debe tenerse en cuenta: a) diversos aspectos esenciales emanados de la cúpula de la juridicidad, como la libertad de información y de comunicación o en general los derechos fundamentales; b) la protección de la esfera privada de los particulares; c) el interés en la educación y las investigaciones; d) la facilitación del arte y la cultura. Para cerrar el complejísimo entramado, a través de todo ello debe dirigirse, además, una cultura floreciente de economías creativas, puestos de trabajo y un mejor "bienestar" general de la sociedad. 
La complejidad regulatoria además se ha de entender por niveles, pues es conocido por todos que la normatividad más importante en materia de derecho de autor o de propiedad intelectual, hace tiempo ya no es expedida por el aparato legislativo de las naciones, sino por una serie de estamentos supranacionales que a través de normas flexibles o soft law, han buscado la unificación paulatina, pero dinámica, de las múltiples normatividades nacionales, e incluso de las contradicciones del copyright con el derecho de autor continental. En donde la complejidad a multiniveles evidencia la verdadera quimera que la doctrina pretende al procurar, de manera legítima pero impracticable, la renovación de una materia con tantos y tantos elementos reverberantes (Sádaba, 2014).

Sin embargo, a estas alturas, si bien es cierto que la pregunta final pareciera estar formulada - cómo debería ser reentendido y modificado consecuentemente el derecho de autor, para poder servir a las exigencias de la sociedad de la información, en la que caímos desde una cascada intempestiva y asincrónica-, parece ahora decisivo nuevamente, analizar la situación en perspectiva más concreta y descriptiva.

De acuerdo al derecho válido, hay muchas más prohibiciones que permisos para el ciudadano. Así, de los particulares se espera que ellos a) tengan conciencia y conocimiento de las posibilidades técnicas que cambian día a día, pero también b) de que sus necesidades personales, respecto de esas innovaciones, no se disloquen y en consecuencia c) que puedan (deban) comportarse de una manera altamente leal a la juridicidad. Ya que ni quieren ni pueden hacer lo anterior, son requeridos, sancionados y demandados por cientos de miles, en todo el globo.

Estas y otras circunstancias han conducido a que el derecho de autor sea catalogado desde una perspectiva externa como injusto. Una masiva pérdida de aceptación y una cada vez más ampliada y difundida "desobediencia civil" en forma de lesiones al derecho de propiedad intelectual, son los efectos, que entre otras cosas, eran perfectamente previsibles desde la entrada en uso generalizado de la web 2.0. Algunos de los grupos políticamente más proactivos internacionalmente, han sido varios de los grandes perpetradores del derecho de propiedad intelectual y del derecho de autor en las redes, como ya se sugirió líneas atrás.

De momento, en perspectiva, solo vale anotar que un efectivo control del internet es casi imposible de lograr. Por supuesto, a fortiori, es más complejo ejecutar sanciones sobre sus usuarios. Cuando un derecho sufre a causa de su pérdida de control o por dificultades en cuanto a su ejecutabilidad o coercibilidad, es relegado 
a una menor aceptación, tanto por parte de los titulares del derecho, como de los destinatarios de las sanciones jurídicas. En similar sentido ver a Pérez (2007).

Para una aceptación permanente y renovada, toda norma jurídica necesita una conciencia de valoración (y no como es afirmado permanentemente por el sordo e inexpresivo corifeo de la dogmática dominante en materia de propiedad intelectual: una "conciencia de lo antijurídico"), tanto por parte del titular de los derechos, pero por sobre todo, por parte de los destinatarios de la norma, para quienes, entre otras, se establecen los efectos jurídicos sancionatorios (al respecto, nótese cómo la parte sancionatoria es uno de los ítems fundamentales del derecho de autor, tratado por la doctrina dominante, contraviniendo la relevante y dominante posición jurídica, que propuso ya a mediados del siglo XX, la casi absoluta patrimonialización de los derechos privados. En Colombia, la Ley 44 de 1993 regula la parte punitiva del derecho de autor, con penas altas y restricciones considerables, que deberían ser analizadas nuevamente. Al respecto véanse: Lipszyc (2006, p. 551); Antequera (2009, p. 705).

Se podría afirmar que hoy en día es más o menos un acto de buena voluntad pagar por la copia de música, películas o software. También podría decirse que cada contenido creado puede recibirse o bajarse de internet legalmente, pero también de manera gratuita. En este segundo evento, el riesgo de una consecuencia jurídica sancionatoria es muy bajo (a pesar incluso de la posible flagrancia en el acto de tentativa o realización); sobre todo si tenemos en cuenta que, como ocurre con no poca frecuencia, se cuenta con el conocimiento técnico necesario para borrar cualquier evidencia.

Aquellos sujetos que en una era digital quieren recibir dinero del usuario final, al otorgarles la posibilidad de acceso, uso, modificación, enriquecimiento, etc., a prestaciones de tipo creativo (creadores profesionales, editoriales, empresas de música, consorcios fílmicos, empresas de software, etc.), son relegados y compelidos a que el usuario "acepte el hecho" de tener que pagar por esas mismas creaciones. Esa dependencia crecerá más, día a día, en el futuro; pues algo parece seguro: ni los viejos tiempos van a regresar, ni será posible, de nuevo en el futuro (próximo, por lo menos), conminar y coaccionar de manera efectiva al usuario a observar el derecho de autor, que, además, hoy en día se niega y viola de manera sistemática. Resulta inocente pensar que se puede coaccionar de manera eficiente en internet a la persona, a través de medios jurídicos e impedirle aquello que el mismo estado de la técnica le permite, sin tener que atentar con derechos de los usuarios, y de 
cierto modo con criterios de justicia material (al respecto véase el caso de la abuela escocesa condenada a tres años de prisión en Escocia, por infringir los derechos de autor, al compartir música a través de redes $\mathrm{P} 2 \mathrm{P}$ ).

Finalmente, desde la perspectiva de este análisis, resulta necesario admitir que la dogmática jurídica, de todos modos, es desarrollada frecuentemente en gran parte por aquellos que fijan posiciones definitivas, (pero de una manera muy personal) para cuestiones no muy delimitadas, pero que además no dejan de ser demasiado complejas, incluso se trata de cuestiones que gravitarían de manera previa, alrededor de necesarios consensos.

También ha de admitirse que las modificaciones fundamentales del derecho de autor no van a conducir a que las innovaciones del mercado y las costumbres de uso comercial o electrónicas se detengan o se devuelvan en el tiempo. Incluso en el mejor escenario posible, la frecuente llamada a la expedición de mejores leyes, distrae en muchas oportunidades del verdadero problema epistemológico del derecho de autor. Las respuestas a las preguntas reales, por ejemplo, ¿cómo ganar dinero en el futuro con los contenidos periodísticos? O, ¿cómo lograr que el mercado de la música de nuevo tenga un balance exitoso a nivel económico? No pueden ser (no son, ni serán) resueltas por la dogmática jurídica. El nuevo derecho de autor mundial, sin embargo, podrá estar en condiciones de fijar, concretamente, importantes condiciones marco para el mercado, si se tienen en cuenta algunos puntos neurálgicos. Si una pieza musical o un libro son más vendidos o no, o si una persona va o no más a cine, son cuestiones que se deciden al interior del mercado y de acuerdo a las condiciones de la libre competencia, expresándolo de manera clara, esas cuestiones no se van a resolver por elucubraciones dogmático-jurídicas reconducentes a normas que además parecen de imposible ejecución.

\section{Bases regulatorias para un derecho de autor moderno}

Hasta aquí, pareciera que nada nuevo ha sido dicho, pero la descripción anterior es un presupuesto necesario para ubicar al lector en el complejo entramado jurídico y económico, que como se evidencia cae lenta pero decididamente en la obsolescencia discursiva y, aún más grave, jurídica. Con relación a las opciones que se ofrecen para una nueva ordenación o por lo menos para una modificación significativa del derecho de autor, parece muy sensato diferenciar entre las perspectivas a corto, mediano y largo plazo. El fundamento para esa priorización es por lo menos a) 
la urgencia o b) la importancia de las respectivas medidas. A lo sumo, desde otra perspectiva, la condición indefectible de que algunas medidas necesitarían más tiempo que otras, para su implementación, realización, puesta en práctica, y con mayor razón, para su efectiva ejecución.

Muchos obstáculos se derivan ya de la formación de la voluntad política diferenciada en cuanto al convencimiento y la determinación para realizar unas u otras modificaciones. Algunos problemas ya fueron reconocidos y señalados como importantes y podrían por ello en un tiempo previsible ser solucionados. Otros inconvenientes no han sido tan siquiera identificados, o no quieren ser reconocidos hasta ahora por la concurrencia de muchos intereses económicos y políticos.

Aún más significativos que los obstáculos políticos, resultan los jurídicos. El derecho de autor está siendo regulado, como quedó sugerido líneas atrás, en convenios internacionales y en normas transnacionales, mundiales, comunitarias europeas y andinas, para restringir de alguna manera la complejísima descripción. Sin embargo, no es del todo cauto olvidar la complejidad supranacional que resulta imposible de clasificar y que acompaña permanentemente a la hipertrofiada regulación de la propiedad intelectual. Las reformas nacionales por lo tanto se condicionan a (o se aplazan hasta) que previamente se reformen, a un estado de deseada permanencia, las normas europeas, andinas, federales, confederativas o internacionales. De allí que todo el planteamiento de soluciones se convierta en un complejísimo proceso, que toma mucho tiempo que, cada vez, parece más valioso.

\section{Medidas en el corto plazo}

Especialmente parecen urgentes de momento varias medidas. Todas ellas son realizables en el corto plazo, en la medida en que no están sujetas a modificaciones en el derecho comunitario andino, en el marco del derecho convencional de la OMPI o en general en el espectro internacional.

Reforma del derecho de contratos en materia de propiedad intelectual. El legislador debería desarrollar el derecho de contratos de autor, por llamarlo de alguna propositiva manera. Este sirve sobre todo para que el creador de conocimiento y obras se proteja dentro de los contratos, que al celebrarse con administradores (casas editoriales, disqueras, etc.) lo perjudican desventajosa y significativamente. Debido a que el autor en los mercados de bienes (obras o creaciones) la mayoría de veces, puede considerarse como el participante débil, 
una protección semejante sería de una alta significación. Así mismo, podrían calcarse su futura arquitectura e implementación de figuras semejantes como el derecho del consumo o el derecho laboral, que no resultan del todo ajenas a los reductos del derecho de autor.

El legislador alemán, por ejemplo, ha reconocido lo anterior y en la reforma del derecho de autor del 2002 incluyó modificaciones de consideración. Entre otras se introdujo la así llamada "pretensión a una remuneración proporcionada" que le otorga el derecho a cada autor o creador para exigir de su contraparte contractual, un pago adecuado y proporcionado frente a su creación. La norma sin embargo ha resultado hasta ahora de muy compleja aplicación, su implementación judicial es bastante difícil, especialmente porque existen asociaciones de autores y de administradores que en muy pocos casos han permitido que se alcance un llamado "acuerdo sobre reglas de remuneraciones comunes", en una cantidad de dinero fija, a la que deba serle reconocida por lo demás una vinculación y aplicabilidad general. La ley prevé que tales reglas generales de remuneración deban ser entendidas concretamente como medidas autorregulativas, sin embargo, deberían ser únicamente normas vinculantes para unificar esas remuneraciones por un tiempo razonable y en casos extremos, esto es, respecto de todos los autores y todas las administradoras de creaciones. Sin embargo, las dificultades aplicativas se siguen presentando.

Todo lo anterior es absolutamente esencial para el creador a la hora de poder obtener una sentencia estimatoria que determine una remuneración razonable, si no existen reglas generales vinculantes sobre el tema, debe el autor, por ejemplo, accionar contra su editorial, o contra el respectivo administrador para discutir y probar la necesidad de una remuneración razonable. Desde el punto de vista de las situaciones complejas del mercado, por ejemplo, con los así llamados periodistas libres, escritores a destajo o traductores bajo modalidades como el freelance, el asunto en una empresa se vuelve muy riesgoso, a lo que se le puede sumar el desprestigio del autor, entre otras variables, si se le vence en el juicio, o si el mismo autor gana para obtener una diferencia de valores mínima a su favor.

La ley en Alemania necesita de finos ajustes para crear una mayor vinculabilidad entre los contratantes. Ello podría ser emprendido en el marco de la próxima reforma a la ley de derecho de autor (que ha sido llamada en la República Federal, como la tercera canasta). Sin embargo, a pesar de las complejidades prácticas y aplicativas, la norma resulta siendo un modelo interesante que, en cualquier marco 
de circunstancias, debe llegar a ser implementado en el corto plazo en muchas latitudes y por supuesto, alguna política al respecto debe desarrollarse en un futuro próximo en Colombia.

\section{Medidas contra las evasiones de las sanciones o su reducción, para efectivizar} la pena. Una corrección urgente y a corto plazo se necesita con relación a las redes de masas contra las sanciones, que sobre todo afectan a la industria de la música, la cinematográfica y la industria de los juegos por parte del usuario final y a causa de lesiones al derecho de autor en lo que se ha denominado "bolsas de intercambio". Cientos de miles de usuarios privados son sancionados a pagar extraordinarias sumas de dinero anualmente a causa del up y download.

Una clase de sanción jurídica semejante perjudica en una considerable medida, como atrás se enunció, la necesaria aceptación de la protección de las creaciones, masivamente.

La condena criminal de personas en países que tienen una compleja situación punitiva y en donde la impunidad también ha hecho carrera, por causas que tienen que ver con la propiedad intelectual, como es el caso de Colombia, pareciera deslegitimar la utilidad del derecho de propiedad intelectual en alguna medida que, si bien resulta criticable desde la dogmática, resulta comprensible desde un punto de vista externo a lo jurídico.

Actualmente parecieran ser los jóvenes quienes atentan masivamente contra el derecho de propiedad intelectual, ya que entre otras razones, son ellos quienes consideran como altamente injustas las sanciones, si se habla todo el tiempo de una sociedad de la información, si se nació en una sociedad de la información, si se vive en una sociedad de la información, si les llamamos los "nativos digitales" restringir la información pareciera ser un contrasentido, desde la más pueril de las lógicas adolescentes; pero tal razonamiento lógico no pierde, por lo mismo, su esencia. En esa aversión sufren además de la sociedad, los principios jurídicos, los creadores y la economía. Si las violaciones al derecho de propiedad intelectual, como actos desobediencia civil, no solo son tolerados sino incluso avalados por parte de una parte de la sociedad, colapsará tarde o temprano el sistema de protección, que se fundamenta en sanciones inejecutables, aparatosamente complejas para alguien del común, y entonces, adicionalmente ilegítimas.

En atención a que las políticas al respecto han resultado poco efectivas, para recabar en la comparación, el legislador alemán ha expedido una norma en el año 2008, que debería hacer poco rentable los requerimientos masivos. El efecto 
deseado de contención permanece excluido, hasta ahora. En realidad, hoy más que nunca son enviadas sanciones a particulares. Por lo tanto, el Ministerio Federal de Justicia ha propuesto un borrador de ley que debería evitar efectivamente las olas de desobediencia, en tanto y cuanto la velocidad después de un número de información se torna exageradamente lenta en up y download. Adicionalmente los contenidos más visitados (piénsese en la canción de moda, buscada en YouTube o un sitio de descargas), luego de determinado número de visitas, también tiende a hacerse lenta en cuanto a su ejecución o su descarga.

\section{Medidas en el mediano plazo}

Facilitación o simplificación del derecho de autor. El desmadre de las sanciones es solo el escape de un problema más complejo que el usuario particular del derecho de autor no entiende o no quiere respetar. Para enfrentar el verdadero problema, un inicial camino, tal y como ocurrió en algún punto del tiempo y como adelante se verá, es que el derecho de autor debería simplificarse fuertemente, o mejor aún, debería eliminar como destinatario último de las regulaciones sancionatorias al usuario particular de la red, y solo entenderlo como un contribuyente que paga por un servicio. Un derecho de autor concebido como hasta ahora to ha pretendido el legislador global, no puede funcionar, en cualquier caso, si de manera directa también se dirige contra particulares.

Una simplificación, que tenga el objetivo de entender al derecho de autor como un ordenamiento de tráfico en las calles de la red, por supuesto, aunque atractivo y deseable, es casi imposible de implementar. El derecho de autor es de momento tan rico en facetas, que para los legos jurídicos podría resultar imposible, respetar cada regla, sin más o menos tener que renunciar con ello totalmente a las cada vez más abiertas libertades de uso. La simplificación máxima en la formulación de los textos legales no alcanzaría, en todo caso, para hacer viable y exitoso el derecho de autor en la pequeña gran aldea global.

Normalmente los particulares no leerán una ley para determinar su comportamiento. Más interesantes resultan aún aquellos antiguos conceptos, que finalmente reconducen a que los particulares nunca pueden atentar contra algunas clases de derechos. En este caso, vale la pena reconducir la discusión a un par de nociones, ellas se basan en la antigua idea fundamental, del derecho romano, según la cual el obrar, los comportamientos de los particulares, son en general permitidos y para 
ello en casos específicos, determinadas remuneraciones integrales son impuestas por el estado, que adicionalmente no pueden ser obviadas como los impuestos de paso, el acceso al agua o a los abrevaderos para los animales: $¡$ Tan pronto se usa, de inmediato se paga! Pero, ¿cómo determinar cuándo se ha usado una creación en la red? Esta sería la pregunta entonces -interpelarían los expertos-.

En el punto más alto del florecimiento del antiguo Imperio Romano, existían abrevaderos a lo largo de los caminos. Independientemente de que se usaran o no, en el torreón de entrada o salida del camino, debía pagarse una suma integral. Para usar creaciones en la red, ¿no es absolutamente necesario entrar a la misma? La regulación de los derechos intelectuales en la red podría ser más sencilla de lo que nos quieren hacer ver los expertos en el tema, pero pareciera que nada nuevo hay entre el cielo y la tierra. Es más, ¿no era eso lo que se pagaba hace mucho tiempo, al comprar casetes vacíos para regalar música grabada en casa, como también ya se sugirió?

La así llamada cuota fija por la cultura. Kulturflatrate en alemán, a manera de ejemplo es un modelo de acuerdo al cual el titular de una conexión a internet debe pagar una tarifa adicional (obligatoria e incondicionalmente). El dinero sería recaudado por parte del proveedor de internet e incluido en la cuota mensual de prestación del servicio. En contraprestación, le es permitido a los particulares compartir, modificar y manipular datos con contenidos protegidos por la propiedad intelectual online; piénsese en el caso de los contenidos subidos a YouTube. Sobre la cuota fija por la cultura se ha discutido en profundidad desde hace más de un lustro en la academia y el foro europeo.

Esta cuota fija funcionaría como otra serie de pagos integrales. Ella contaría con la gran ventaja de que todos los comportamientos diarios son permitidos, cobrados y recaudados sin ninguna posibilidad de evasión. El usuario no debe conocer, dependiendo de cómo se configure la norma legal, ninguna particularidad, ni detalle del derecho de propiedad intelectual regulado por la ley. Permitido es, lo que el estado de la técnica digital le brinde al usuario y por ello se debe pagar.

Sin embargo, existen diversos motivos por los cuales la cuota fija por la cultura no tiene mucho éxito en el debate político. Visto jurídica y políticamente, ella resulta problemática, porque para implementarla fundamentalmente deberían reformarse las directrices europeas y suramericanas (CAN o Mercosur) sobre el tema. A nivel económico también resulta dificultosa por cuanto no queda claro cómo afectaría o modificaría el intercambio de datos legítimo a los modelos de 
negocios aún novedosos en la versión online, por ejemplo, la industria fílmica y musical. En materia de política social también ella, como cada cuota fija, resulta compleja, pues mucha gente debe pagarla, con las posibilidades otorgadas, que no pueden o no quieren utilizar. Por ejemplo, un ciudadano que no escucha música en la red o no ve películas, no sube contenidos ni originales, ni modificados a YouTube, ni a ninguna plataforma del mal llamado to share debería pagar una cuota, independientemente de que comparta o no esa clase de datos, solo por el hecho de tener una conexión a internet.

Al respecto se muestran igualmente disonantes aquellos que encuentran dificultades en cuento a la aplicación del ya mencionado "canon digital", ya que enuncian problemáticas desde lo formal, como que no todos los equipos de reproducción digital involucran obras protegidas, hasta de fondo, en tanto que estas cargas económicas representan en la cadena de producción y consumo de una obra, obstáculos que entorpecen el desarrollo y la diversificación de la cultura, pues riñe con la naturaleza pública de la cultura en sí. En otras palabras, restringe el "dominio público de la cultura" (Padrós y López, 2011).

Por otro lado, hay buenos motivos para una solución como esta; sobre todo desde el punto de vista del insoportable estado de cosas, por virtud del cual, miles de millones de personas emprenden la ejecución de comportamientos antijurídicos (atentatorios del derecho de autor), y por ello no se paga ninguna clase de compensación monetaria a favor del autor de la obra, a menos que solo una mínima porción de esas personas (es imposible perseguirlas y sancionarlas a todas) sean sancionadas con drásticas medidas jurídicas. A pesar de todas las desventajas del hecho concreto de imponer la cuota fija (flatrate), se encuentra el principio retrospectivo de entender al usuario privado en la igualación del derecho de propiedad intelectual, solo como el "usuario que paga", si se quiere como un contribuyente y no como un destinatario activo de la regulación que debe ser avezado y experto en los temas, con lo que a mediano y largo plazo, ante la inminente complejización técnica del tema, puede entenderse la medida, como la única correcta. Al respecto, la experiencia alemana de la introducción de la regulación de la copia privada ya para 1966, queda como evidencia empírica de las ventajas de la medida “exigir remuneración, por lo que no se puede controlar, permite no prohibir". En esa medida el modelo debería ser analizado con detenimiento antes que hacer aseveraciones lapidarias para rechazarlo, como en efecto ha ocurrido en el foro internacional de la propiedad intelectual. 


\section{A modo de conclusión: medidas en el largo plazo, giro radical en la finalidad aisladora del derecho de autor}

El moderno derecho de autor fue ya establecido, desde sus inicios, con el argumento de la necesidad de protección. La conexión personal-espiritual entre creador y obra debería ser concebida de manera igualitaria al otorgamiento de una fuente de ingresos. Traído del espíritu del tiempo del romanticismo tardío y de la ilustración, el derecho de autor se explicó entonces desde la iusfiolosofía como "algo" que no necesitaba ninguna clase de fundamentación o justificación. En general, se entendió como un derecho natural que debería caracterizarse como la "propiedad inmaterial" (o espiritual).

$\mathrm{Al}$ observar el asunto con una mayor precisión, es claro que el derecho de autor ya no se corresponde más con esa noción fundamental. Es más, con una observación que puede ser muy controvertida pero más precisa, puede afirmarse que ese nunca fue el caso. En cuanto a la naturaleza del derecho de autor, el pensamiento es en realidad muy justificado y debería (nuevamente) ser fructífero. Se podría de manera astuta decir que el derecho de autor hoy en día es, sobre todo, un instrumento político-industrial, para cumplir los intereses económicos de ciertos grupos. Contra la protección de los intereses económicos sobre los derechos de bienes inmateriales, no hay ningún argumento en contra; pero contra la aplicación manipuladora de argumentos y de esquemas de argumentación, por supuesto sí. Estas conducen a decisiones políticas erradas y a una confusión del estado de cosas.

Argumentar con los intereses de los creadores es muy ventajoso, por supuesto, en la opinión pública y política. ¿Qué puede argumentarse contra un derecho que protege a los creadores, frente a que sus obras y logros en innovación sean hurtados, y que, a ellos, por lo demás, les otorgue un fundamento económico para su subsistencia? ¿Quién puede argumentar contra el hecho de que ese derecho se garantice por la vida del autor y un corto periodo adicional, que le garantice ese bienestar económico al autor y a sus herederos?

Que el derecho de autor al respecto ha sido significativamente manipulado, lo evidencia sobre todo la circunstancia de que a pesar que el autor desde siempre necesitó protección, sobre todo y especialmente frente a su contraparte contractual (el editor, el productor de la película, etc.), siempre se configuró como si el autor debiera estar más o menos en todas las posiciones jurídicas imaginables ejerciendo sus derechos, de manera plena, de manera tal que le brindaran alguna clase de 
beneficio patrimonial, situación que en realidad en muy raras oportunidades se ocurria. Bajo el mandato de la libertad contractual, se ha dejado en la mayoría de los casos al administrador — por supuesto mucho más fuerte contractualmente- el diseño de si, cuándo, cómo y en qué cantidad el autor recibe los pagos y qué otros derechos tiene.

Solo los intereses morales y los llamados derechos de la personalidad le permanecen intangibles al autor y son perpetuados en igualdad de condiciones, digamos no pueden ser afectados por los acuerdos contractuales celebrados con las entidades administradoras (editoriales, productoras, etc.). Semejante sistema legal por supuesto no resulta apropiado desde ningún punto de vista, es dable pensar, ni siquiera se compadece con la exigencia de brindarle unos mínimos ingresos al autor.

La asociación perpetuada legislativamente en el derecho de autor, entre autor y editorial (o creador y administradora, en términos más generales), es una genialidad de los grandes emporios de la economía creativa y por supuesto una de las más exitosas empresas del lobby de la modernidad. Ella es el fundamento para que en los debates sobre derechos de autor puedan ser puestos como pretextos los aspectos morales, románticos y culturales de una manera bastante exitosa. Sin embargo, resulta claro que casi exclusivamente el tema de las políticas legislativas en materia de derecho de autor se reduce a mantener monopolios para maximizar las ganancias de manera permanente a favor de empresas discográficas, editoriales o fílmicas, manteniendo en precarias situaciones a los creadores.

Esa mezcla de funciones totalmente diversas en un único "derecho de autor" reconduce a masivas ineficiencias y con ello a buscar proteger intereses diversos y exigencias que bloquean la protección cierta de prestaciones creativas individuales y colectivas. Todas estas son los grandes desafíos y los más importantes puntos de observación para las futuras reformas del derecho de autor. Una solución conceptual reposaría en que los intereses del autor y de las editoriales (si se quiere los derechos del creador y de las administradoras) fueran separados en su tratamiento legislativo de manera sistemática y regular; de manera tal que se pudiera crear un verdadero derecho de autor, un derecho de autor "más adecuado", que permitiera ajusticiar, en realidad, los derechos de los creadores y autores, incluso los de los administradores y editoriales (que por ejemplo, como elemento esencial al lado de los derechos de personalidad tratase el tema de un derecho contractual tuitivo y potencial a favor del autor-creador). 
Sería necesario que al lado del derecho de autor fuesen creados derechos económicos especiales que igualaran los intereses económicos de las administradoras, así como también un derecho que permitiera asegurar la libre competencia funcional, derechos diversos a los de protección de las creaciones actuales (que como derechos de protección derivados del derecho de autor, son propuestos sin que pueda argumentarse sólidamente ni su etiología ni su necesidad de fortaleza).

\section{Referencias}

Antequera, P. R. (2009). Estudios de derecho industrial y derecho de autor (análisis de jurisprudencia comparada). Bogotá: Pontificia Universidad Javeriana, Facultad de Ciencias Jurídicas.

Beck, U. (2008). Generaciones globales en la sociedad del riesgo mundial. Fundación CIDOB. Eco, U. (2007). A paso de cangrejo: artículos, reflexiones y decepciones, 2000-2006. Madrid: Debate. Ficsor, M. (2008). Limitaciones y excepciones al derecho de autor en el entorno digital. Bogotá: Organización de las Naciones Unidas para la Educación, la Ciencia y la Cultura.

Gómez, A. (2017, julio-diciembre). Elaboración del guion instruccional mediante la herramienta didáctica del recurso educativo digital. Revista Via Inveniendi et Iudicandi, 12(2), pp. 149-180. DOI: http://dx.doi.org/10.15332/s1909-0528.2017.0002.06. Recuperado de http://revistas.usantotomas.edu.co/index.php/viei/article/view/3751/3713

Hurtado, M. (2017, julio-diciembre). Crisis de la forma jurídica y el despertar antisistémico: una mirada desde el pluralismo jurídico de las Juntas de Buen Gobierno (JBG). Revista IUSTA, (47), 19-33. DOI: http://dx.doi.org/10.15332/s1900-0448.2017.0047.01. Recuperado de http://revistas.usta.edu.co/index.php/iusta/article/view/3810/3749

Kreutzer, T. (2012). Auf dem Weg zu einem Urheberrecht für das 21. Jabrbundert: Ideen für eine zukünftige Regulierung kreativer Güter. Springer Heidelberg: Wirtschaftsdienst 1613978X Springer Heidelberg 92201210 699-705.

Lipszyc, D. (1993). Derecho de autor y derechos conexos. Buenos Aires: UNESCO.

Padrós, C., y López, J. (eds.) (2011). El Canon Digital al debate. Revolución tecnológica y consumo cultural en un nuevo marco jurídico económico. Barcelona: Atelier. Libros Jurídicos.

Pérez, B. H., y Korneli, C. (2007). Manual de técnica legislativa. Buenos Aires: Educa. Pontificia Universidad Católica Argentina y Konrad-Adenauer-Stiftung (Argentina).

Sádaba, I. (2014). La tragedia del copyright, bien común propiedad intelectual y crisis de la industria cultural. Revista: Anales de Documentación. Barcelona: Universidad de Murcia.

Tato, A. (2008). La reforma de la ley de propiedad intelectual y los límites al derecho de autor: copia privada, canon digital y press clipping. Vigo, España: Universidad de Vigo. 